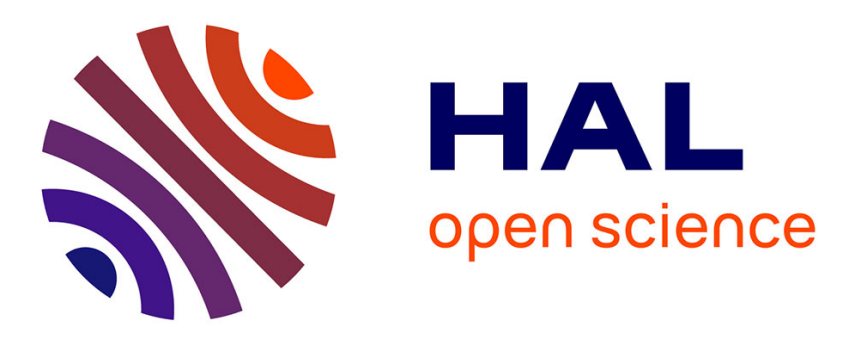

\title{
Grumpy face during adult sleep: A clue to negative emotion during sleep?
}

Jean-Baptiste Maranci, Alexia Aussel, Marie Vidailhet, Isabelle Arnulf

\section{To cite this version:}

Jean-Baptiste Maranci, Alexia Aussel, Marie Vidailhet, Isabelle Arnulf. Grumpy face during adult sleep: A clue to negative emotion during sleep?. Journal of Sleep Research, 2021, pp.e13369. 10.1111/jsr.13369 . hal-03217683

\section{HAL Id: hal-03217683 \\ https://hal.sorbonne-universite.fr/hal-03217683}

Submitted on 5 May 2021

HAL is a multi-disciplinary open access archive for the deposit and dissemination of scientific research documents, whether they are published or not. The documents may come from teaching and research institutions in France or abroad, or from public or private research centers.
L'archive ouverte pluridisciplinaire HAL, est destinée au dépôt et à la diffusion de documents scientifiques de niveau recherche, publiés ou non, émanant des établissements d'enseignement et de recherche français ou étrangers, des laboratoires publics ou privés. 
Grumpy face during adult sleep: a clue to negative emotion during sleep?

JEAN-BAPTISTE MARANCI, ${ }^{1,2,3}$ ALEXIA AUSSEL, ${ }^{1}$ MARIE VIDAILHET, ${ }^{2,3}$

ISABELLE ARNULF ${ }^{1,2,3}$

1 Sleep Disorder Unit, Pitie-Salpetriere University Hospital, APHP, Paris, France

2 Brain and Spine Institute - ICM; IHU@ICM, Paris

3 Sorbonne University, Paris, France

Correspondence to: Isabelle Arnulf, Service des Pathologies du Sommeil, Hôpital Pitié-Salpêtrière, 47-83 Boulevard de l'Hôpital, 75651 Paris Cedex 13, France

E-mail: isabelle.arnulf@aphp.fr; phone: 331421677 02; fax: 33142167700.

Submitted to: Journal of Sleep Research, version 2

Running Title: Negative facial expressions during sleep 


\section{ABSTRACT}

Negative facial expressions and frowns have been studied (albeit more rarely than smiles) in foetus' and neonate' sleep, but they have not been investigated during adult sleep. Videopolysomnography (including corrugator muscle electromyography and face focused video) was used to study negative facial expressions in sleeping adults, including healthy subjects and patients with/out parasomnia. Frowns were observed during sleep in 89/91 (97.8\%) adults during normal (29 healthy subjects) and abnormal sleep (29 patients without parasomnia, 15 patients with disorders of arousal and 18 patients with REM sleep behaviour disorder [RBD]). In healthy subjects, the following events occurred in decreasing frequency: isometric corrugator activations, brief frowns, and then prolonged frowns and raised eyebrows (both similarly rare). Frowns predominated in REM sleep, and had a lower frequency in NREM sleep. In healthy subjects, frowns were elementary and not associated with other face movements to the point of composing negative expressions. In contrast, frowns were occasionally associated with overt negative facial expressions in REM sleep in patients with RBD and a young patient with night terrors. They included mostly painful expressions and rarely sadness and anger, in link with apparently negative behaviours (shouts, painful moaning, speeches). Frowns persist during normal sleep (mostly in REM sleep) in adults, but overt negative facial expressions are restricted to patients with parasomnia. Whether elementary frowns translate a negative dream emotion should be determined, but overt negative facial expressions during RBD could be used as a direct access to dream emotions.

Keywords: corrugator, frowning, facial expression, parasomnia, sleep 


\section{INTRODUCTION}

Facial expressions are a form of non-verbal communication found in all human cultures (Ekman \& Friesen, 1969). Among them, negative facial expressions include some of the basic emotions described by Eckman et al., e.g., anger, fear, disgust and sadness, or pain (which is not an emotion but is also manifested by facial expressions) (Craig et al., 2011). Facial expressions have both an adaptive role to a threat and a social role in communicating affects (Schmidt et al. 2001). Negative expressions, however, appear in the foetus before any interaction with the environment or other human beings (Kurjac et al., 2006). Scowling face is observable from 20 weeks of life in utero. The first crying and painful faces are present from 24 weeks and become increasingly complete during the development of the foetus (Reissland et al. 2011 and 2013). After birth, neonates commonly frown during active sleep, which will subsequently become REM sleep (Emde et al., 1969). Frowns are not a facial expression on their own but are always present during negative expressions such as anger, sadness or pain (Eckman et al., 2002, Craig et al. 2011).

In adults, the persistence of frowns or other negative facial expressions has been studied little and by indirect means. To date, studies have been limited to the correlation of electromyographic (EMG) recordings of facial muscles, especially the corrugator, used to frown when awake with negative feelings (Larsen et al., 2003). Sustained EMG corrugator activations lasting more than 6 seconds have been observed during REM sleep in subjects with vivid dreams and in patients with depression (Perlis et al., 1991, 1995). In healthy subjects, phasic activities of muscles involved in facial expressions such as the corrugator, orbicularis oculi, frontalis and zygomaticus are recorded in all sleep stages but clearly predominate during REM sleep (Rivera-Garcia et al. 2011). In addition, the activities of these muscles are associated. In particular, corrugator and orbicularis oculi activities correlate during the expression of anger, whereas corrugator and frontalis activities correlate during the expression of fear. These observations suggest that frowning and other negative expressions may persist during adult sleep. None of these studies, however, has been combined with a video recording of the sleeper's face to verify whether these muscle activities translate into face movements. Along these lines, a recent study focusing on positive expressions during sleep was able to 
describe rare smiles during adult sleep due to recordings of the zygomaticus muscle (Clé et al., 2019).

The study objective was to look for the presence of frowning and negative expressions during sleep in adults, using corrugator muscle monitoring during polysomnographic recordings of sleep combined with a video recording of the sleeper's face. The background idea was to find a way to access sleeper emotions. In addition to studying healthy adults, we examined whether patients with sleep disorders have an increase in these negative emotions. Based on previous studies (Clé et al., 2019), we expected to find more frequent negative facial expressions among patients with REM sleep behaviour disorder (RBD), a condition involving enacted dreams associated with loss of normal REM sleep atonia.

\section{METHODS}

\section{Subjects}

The participants comprised healthy subjects and patients referred to the sleep disorders unit of the Pitié-Salpêtrière University Hospital in Paris to carry out a clinical diagnosis or were included in observational trials of undisturbed sleep (NCT02305147 and NCT03074578). All participants were interviewed by a psychiatrist and a sleep specialist (JBM). Sleep disorders were defined according to international criteria (American Academy of Sleep Medicine, 2014).

Patients with sleepwalking and night terrors were categorized as suffering from "disorders of arousal" (DOA). The subjects were then divided into four groups: i) healthy subjects without any sleep disorder; ii) patients with sleep disorders excluding parasomnias; iii) patients with DOA; and iv) patients with RBD. All participants gave oral or written consent after receiving explanations from a physician, depending on whether they were taking part in a research study or were referred for clinical purposes. In the latter case, the French Jardé law on research waives the requirement for written consent and allows the post hoc study of clinical observational measures for research purposes, provided that the participant does not oppose (i.e., non-opposition after being provided information) and that anonymization 
of analysis is warranted (MR003, No 1999732). The study was approved by the local ethics committee (Comité de Protection des Personnes lle-de-France VI).

\section{Sleep evaluation}

The participants completed an Epworth sleepiness scale (Johns, 1991). The participants underwent one or two successive video-polysomnographies. Patients referred for a suspected parasomnia (DOA or RBD) or a central disorder of hypersomnolence were systematically scheduled for two consecutive nights in order to increase the diagnostic accuracy, whereas a second night was occasionally scheduled in subjects with other sleep symptoms, depending on their clinical context. The polysomnographic recordings took place between 10 p.m. and 6 to 8 a.m. The channels included Fp1-A2, C3-A2 and C3-O1 electroencephalographic (EEG) derivations, bilateral electrooculography (EOG), nasal pressure, naso-oral thermistor, respiratory abdominal and thoracic efforts through plethysmography, tracheal sound recording, electrocardiography, pulse oximetry, and EMG recording of the levator menti and bilateral tibialis anterior muscles (Compumedics Ltd, Victoria, Australia). In addition, two surface electrodes were placed on corrugator muscles for bipolar monitoring. The scan rate was $256 \mathrm{~Hz}$ for all derivations. According to the American Academy of Sleep Medicine criteria, a $0.3-35 \mathrm{~Hz}$ filter was applied for EEG channels and a 10-100 Hz filter was applied for EMG channels, including the corrugator EMG.

\section{Evaluation of facial expression during sleep}

The entire PSG recording was viewed in 30-second epochs, including the EMG channels. Awakenings and arousals were carefully excluded from the corrugator analysis. For each sustained EMG activation of the corrugator, defined as as any waveform exceeding the baseline activity by $500 \%$ and lasting longer than $0.1 \mathrm{~s}$, the video was visually inspected (Rivera-Garcia et al., 2011). Videos with EMG activation but no observable eyebrow movements were scored as E0 (isometric muscle contractions); visible frowns were scored as $E 1$ then subdivided into brief $(<1 \mathrm{sec}$, scored as E1a) and prolonged (> $1 \mathrm{sec}$, scored as E1b) frowns; and raised eyebrows were scored as E2 (resulting from a co-contraction of the corrugator and the frontalis) (illustrations in Figure 1). In addition to this classification, the scorers focused their attention on the entire face and subjectively determined whether the sleeper exhibited a negative expression. To do this, they relied on Eckman's description of 
basic negative expressions (sadness, anger, disgust, fear) and on available descriptions of painful faces (Eckman et al., 1978, Craig, 2011). The Facial Action Coding System (FACS) method was not used. In addition, the behaviours (apart from the facial expression) evocative of a negative experience were recorded (e.g., shouting, crying, emotional speech, fighting). Two judges scored the events. Eleven $(9.8 \%)$ nights were double scored, leading to a between-scorer agreement rate of $76 \%$ (calculated by dividing the number of events scored identically by the two judges by the total number of events scored by either judge).

\section{Statistical analysis}

Quantitative measures are described as the means $\pm S D$, and categorical measures are described as percentages. Since the number of nights varied between subjects, the night was used as the unit of analysis for statistical comparisons. The betweengroup differences were tested using a Kruskal-Wallis test for quantitative measures and a Fisher's test for the categorical measures. In case of significance $(P<0.05)$, the groups were then compared two by two using a Mann-Whitney test for the quantitative measures and a chi-square or Fisher's test depending on the validity of the conditions for the categorical measures. A post hoc Bonferroni correction was applied with a significance level set at $P<0.008(0.05 / 6)$. For comparisons of within-subject measures, a Mann-Whitney test was used. Correlations were performed using a nonparametric Spearman test. The statistical software was $R$ ( $R$ core team, 2020).

\section{RESULTS}

\section{Sample characteristics}

A total of 127 participants were included. Then, 36 subjects were excluded from the analysis mainly due to dysfunction of the EMG sensor or to an inability to see the face (e.g., patients sleeping under the sheet, lying ventrally, or using a night mask). In the remaining 91 subjects (studied over 114 nights), when the face was not visible for a limited portion of the night, these sequences were also excluded from the analysis. The participants included in the final analysis comprised 29 healthy subjects (31 nights), 29 patients without parasomnia (37 nights) (includes patients with 
obstructive apnoea syndrome, $\mathrm{N}=8$; Parkinson's disease and no concomitant RBD, $\mathrm{N}=6$; idiopathic hypersomnia, $\mathrm{N}=4$; insomnia, $\mathrm{N}=3$; restless legs syndrome, $\mathrm{N}=3$; atypical fainting, $\mathrm{N}=2$; Steinert disease, $\mathrm{N}=1$; and epilepsy, $\mathrm{N}=1$ ), 15 patients with DOA (22 nights) and 18 patients with RBD (24 nights) (includes patients with Parkinson's disease, $\mathrm{N}=9$; idiopathic RBD, $\mathrm{N}=8$; and narcolepsy, $\mathrm{N}=1$ ). In the 23 patients who were monitored during two consecutive nights, the sleep efficiency and wakefulness index did not differ between the two nights (Wilcoxon test, $p=0.74$ and $p=0.9$ respectively). Demographic characteristics and questionnaire data are presented in Table 1. The sex ratio was not different across groups. The healthy subjects were younger than the patients without parasomnia and those with RBD, and the patients with DOA were younger than those with RBD and without parasomnia. As expected by the primary disorders, the healthy subjects were less sleepy than the patients without parasomnia and patients with DOA.

\section{Corrugator activations and eyebrow movements}

All subjects exhibited corrugator phasic activations. A total of 6,593 corrugator activations, including 2,086 frowns, were observed. The various facial expressions according to corrugator activation are shown in Figure 1 (anonymizing faces to avoid facial recognition but reflecting exact expressions). Asymmetrical frowning was observed on two occasions ( $0.1 \%)$, and asymmetrically raised eyebrows ("Jack Nicholson" eyebrows) were observed on one occasion in two patients with RBD. They were counted along with the other frowns and raised eyebrows for the analysis. The prevalence of subjects who presented at least one observable event categorized by the type of event (E1, E1a, E1b or E2) and the sleep stage is presented in Table 2. Almost all (97.8\%) subjects frowned at least once during sleep, with the exception of two patients without parasomnia. The frequency of all events (E0, E1, E1a, E1b, E2) per hour of sleep (or index) depending on the group of subjects and on sleep stages is shown in Table 3.

\section{Corrugator activation and eyebrow movements in healthy subjects}

In the healthy group (Table 3 and Figure 2A), the corrugator activation index without observable facial movements (E0) was higher than the index of any other event (E1a, $E 1 b$ and $E 2)$ during sleep. Brief frowning $(E 1 A)$ was more frequent than prolonged 
frowning (E1B) and raised eyebrows (E2). The index of prolonged frowning and raised eyebrows did not differ. The index of all corrugator activations (E0 + E1 + E2) was higher in REM sleep than in any other sleep stage (N1, N2 and N3) (Figure 2B) and lower in N1 than in N2 and N3. The index of corrugator activations was similar in $\mathrm{N} 2$ and in N3. Likewise, frowning was more frequent in REM sleep than in any other stage, followed by stages N2 and N3 (similar frequencies) and then stage N1 (Figure 2C). There was no sex difference in the corrugator activation index or the frowning index. There was no correlation between these two indexes and the age of the participants $(P>0.05$ for all comparisons).

\section{Corrugator activation and eyebrow movements in patient groups}

The patients with RBD had more visible eyebrow movements during REM sleep than other groups. They had higher indexes of prolonged frowning (5.8 times more frequent) and raised eyebrows (15.2 times more frequent) than the healthy subjects during REM sleep, but brief frowning and corrugator activations without movement were not different. In contrast, the patients with RBD and healthy subjects had a similar prevalence and index of corrugator activations in NREM sleep (stages N1, N2 and N3). The healthy subjects showed no difference from the patients with DOA. The patients without parasomnia had lower frequencies of corrugator activations than the other groups, in a way that varied with the type of event and the sleep stage. In the 23 subjects (healthy subjects or patients) having undergone polysomnography during two successive nights, there was no difference between Night 1 and Night 2 for any of the events, regardless of the sleep stage $(P>0.05$ for all).

\section{Negative expressions during sleep}

None of the participants from the healthy group or from the group of patients without parasomnias exhibited what was judged as negative expressions or negative behaviour during sleep. In the RBD group, 8/18 (44\%) patients presented negative expressions, corresponding to $9 / 24$ (38\%) nights. A total of 29 negative expressions over 24 nights were observed, exclusively during REM sleep, corresponding to an index of $0.85 / \mathrm{h}$ of REM sleep. Among these expressions (Figure 3), 25 had the characteristics of the facial expression of pain, including frowning, tightening of the eyelids, elevating the cheeks, horizontal stretching of the lips, oblique pulling at the corner of the lips, vertical stretching of the open mouth or wrinkling the nose. Six of 
these pain expressions were associated with a brief shout or a moan. The other expressions included three expressions of sadness with a combination of lowering the outer eyebrows, raising the inner eyebrows, and lowering the lip corners and one angry expression with frowning, raising the upper lid, and tightening of the mouth. The duration of these expressions varied between 2 and $11 \mathrm{sec}(4.9 \pm 2.3 \mathrm{sec})$. The expression of anger followed a complex scenario accessible through the patient's speech and gestures. The patient said: "Give him 5 euros... Give him 5 euros! Give him 5 euros and you pay for moms' stuff! Yeah, yeah!" and then suddenly slapped, concomitantly with the expression of anger. The patient then calmed down, and the scenario continued when he said, "Don't be afraid, I'm calm".

Otherwise, in ten other instances, we could not identify a negative expression based on the pattern of muscle contractions of the face, but frowns were associated with characteristics suggestive of a negative event, including shouting $(N=1)$, crying $(N=$ 3), painful moaning $(\mathrm{N}=4)$, angry speech and gestures $(\mathrm{N}=1)$ and a fight $(\mathrm{N}=1)$. Among the patients with DOA, only one (with night terrors) exhibited an expression of anger associated with upper limb movements during REM sleep.

\section{DISCUSSION}

\section{Main findings}

Frowns persisted during normal adult sleep and disordered sleep. There was a gradual decrease in the prevalence and frequency of these events from simple, isometric corrugator activations to brief frowning and then prolonged frowning and raised eyebrows (which were similarly rare). Frowns predominated in REM sleep, although they were also present (with a lower prevalence and frequency) in NREM sleep. Although frowning while asleep was not associated with other face movements to the point of composing actual negative expressions in healthy subjects or in patients, this did occur in patients with RBD and an isolated young patient with DOA. Painful expressions were frequent in patients with RBD, whereas sadness and anger were rarely observed.

\section{Corrugator activation in healthy sleepers}


Our results in 29 healthy subjects partly reproduced those obtained in 6 healthy subjects (Garcia-Garcia et al, 2011). Both studies found a dramatically higher activity of the corrugator in REM than in NREM sleep, but the activation index in NREM sleep differed across stages, with a descending activity from N1 to N2 and then N3 in their case and the reverse in our study. The corrugator activation index was lower (20.3/h of REM sleep) in the present study than in this previous work (135.8/h of REM sleep). These discrepancies can be explained by the limitation of EMG events to those lasting more than $100 \mathrm{~ms}$ in our study vs. $1 \mathrm{~ms}$ in the previous study. Here, we aimed to capture face movements, which require minimally prolonged EMG activation.

\section{Frowning persists in adult sleep}

As in neonates, frowns occur during adult sleep. However, their frequency is lower in adults (index of 5.8/h of REM sleep) than in neonates (30 to $48 / \mathrm{h}$ of agitated sleep) (Emde 1969, Challamel 2018). The patients with RBD had a frowns index of 13.1/h of REM sleep, which was intermediate between the neonate and healthy adult rates. The frowns index in adults without parasomnia was dramatically higher than the smile index found in a previous sample of adults without parasomnia (Cle, 2019). In a larger population, only 9 smiles and 10 unilateral contractions of the zygomatic muscles were observed, reaching a cumulative frequency of 0.023 events/h of total sleep time compared to the 2.33 frowns/h of sleep observed in the present study (for the healthy subjects group), i.e., approximately 100 times higher. Previous studies simultaneously recording the EMG of corrugator and zygomaticus muscles have reported a higher index for the corrugator than the zygomatic (Garcia-Garcia et al, 2011), although the differential was lower (approximately 2 times higher).

\section{Negative expressions in patients with RBD}

Several authors have reported negative facial emotions during REM sleep in patients with RBD. Frauscher et al. (2007) observed 40 complex behaviours and 26 vocalizations associated with apparently negative emotions during 9 nights in 5 PD patients with RBD. Oudiette et al. (2009) reported 30 apparently negative sequences in 136 videos of RBD-associated motor events recorded in patients with RBD. Bugalho et al. (2017) reported 1.9 negative emotions per hour of REM sleep in PD patients with RBD and 12/h in patients with idiopathic RBD. The present study 
analysed the apparent emotions of the patients with RBD in more detail. Among the events that we classified as apparently negative, only some exhibited the characteristics of basic emotions, including characteristic faces of sadness and anger. Most had features of painful faces, which may indicate physical pain or, more generally, an unpleasant and negative experience. Other events showed incomplete expression (e.g., frowns) but in association with other behavioural cues indicating negative emotion.

\section{Do frowns correspond to bad dream enactment?}

In healthy subjects, prolonged (> $1 \mathrm{sec}$ ) frowns subjectively appear to be more than just REM sleep-associated muscle twitches because they were bilateral, longer than $1 \mathrm{sec}$ and led to visible changes in facial expression. In healthy subjects, frowns were not associated with visible contractions of other facial muscles suggestive of basic negative emotions or pain (whereas rare Duchenne smiles are found in healthy adults). Frowns were also not associated with other behaviours suggestive of a negative experience, such as screaming or crying, but such enactment would be unexpected in healthy subjects. In the absence of these clues, one approach to determine whether frowns truly translate an inner negative emotion would be to wake the sleepers after each frown and collect their dream report and felt emotions. It is tempting to imagine an overrepresentation of negative dreams collected after these events. In the study of Rivera-Garcia et al. (2018), subjects were awakened after minor corrugator EMG activations and completed dream emotion questionnaires, but they did not find more negative dreams. One can, however, imagine a different result by limiting oneself to the observable frowns, which could denote a more intense emotional activation than simple EMG activations do. One way to circumvent this limitation of awakening subjects to obtain dream reports is to observe complete dream-enacting behaviours in patients with RBD. In our study, these patients had either some isolated frowns that were not associated with other clues to infer their inner emotion (and this was frequently the case) or, more rarely, displayed complex facial expressions, including these frowns and behavioural clues (e.g., screams, aggressive speeches, fighting) evoking negative emotions. At this point, the question of whether frowns correspond to dream enactments remains unanswered, except for 
a limited number of frowns in patients with RBD, which clearly correspond to enactment of bad dreams.

\section{Limitations}

Our study has some limitations. The group of patients without parasomnia was heterogeneous in terms of diagnoses, rendering the differences with the other groups difficult to interpret. The between-groups differences in the frequency of the various events may have been influenced by their heterogeneity, particularly in terms of age. The study did not include provoked awakenings following frowns and their associated dream recall, which does not allow to make a direct link between frowning and negative emotion of the corresponding dream.

\section{Conclusion}

Frowns persist during adult sleep, but their link with dream emotions has yet to be determined. On the other hand, negative facial expressions are visible in patients with RBD, and they are sometimes associated with other behavioural cues revealing a negative dream. These sequences could be used as direct access to the dream emotion and, if confirmed, could help to better understand the function of negative emotions during sleep.

\section{Conflict of interest}

All authors declare that they have no conflicts of interest related to this study.

\section{ACKNOWLEDGEMENTS}

The authors thank Lucy Doherty for the illustrations. The study was promoted by Assistance Publique - Hôpitaux de Paris and by INSERM.

\section{AUTHORS' CONTRIBUTION}

Participants were interviewed by JBM. Events were scored by JBM and AA. The statistical analysis was performed by JBM. JBM and IA wrote the first version of the article, which was then proofread by all co-authors. The study was promoted by IA and MV. 


\section{References}

American Academy of Sleep Medicine (2014). The international classification of sleep disorders (3rd ed.). Darien, IL: American Academy of Sleep Medicine.

Bugalho, P., Lampreia, T., Miguel, R., Mendonça, M., Caetano, A., \& Barbosa, R. (2017). Characterization of motor events in REM sleep behavior disorder. Journal of Neural Transmission, 124(10), 1183-1186.

Challamel, M. J., \& Lalhou, S. (2018). Spontaneous smiling and facial mimics in the neonate: A contribution to the functional role of paradoxical sleep during development. Neurophysiologie Clinique, 48(3), 131.

Craig, K. D., Prkachin, K. M., \& Grunau, R. E. (2011). The facial expression of pain.

Emde, R. N., \& Koenig, K. L. (1969). Neonatal smiling, frowning, and rapid eye movement states: II. Sleep-cycle study. Journal of the American Academy of Child Psychiatry, 8(4), 637-656.

Ekman, P., \& Friesen, W. V. (1969). The repertoire of nonverbal behavior:

Categories, origins, usage, and coding. Nonverbal communication, interaction, and gesture, 57-106

Ekman, P., Friesen, W., \& Hager, J. (2002). Emotional facial action coding system. Manual and investigators guide. CD-ROM. Salt Lake City, UT: Human Face.

Emde, R. N., \& Koenig, K. L. (1969). Neonatal smiling, frowning, and rapid eye movement states: II. Sleep-cycle study. Journal of the American Academy of Child Psychiatry, 8(4), 637-656. 
Frauscher, B., Gschliesser, V., Brandauer, E., Ulmer, H., Peralta, C. M., Müller, J., ... \& Högl, B. (2007). Video analysis of motor events in REM sleep behavior disorder. Movement disorders: official journal of the Movement Disorder Society, 22(10), 1464-1470.

Kurjak, A., Andonotopo, W., Hafner, T., Kadic, A. S., Stanojevic, M., Azumendi, G., ... \& Troyano, J. M. (2006). Normal standards for fetal neurobehavioral developmentslongitudinal quantification by four-dimensional sonography. Journal of perinatal medicine, 34(1), 56-65.

Larsen, J. T., Norris, C. J., \& Cacioppo, J. T. (2003). Effects of positive and negative affect on electromyographic activity over zygomaticus major and corrugator supercilii. Psychophysiology, 40(5), 776-785.

Oudiette, D., De Cock, V. C., Lavault, S., Leu, S., Vidailhet, M., \& Arnulf, I. (2009). Nonviolent elaborate behaviors may also occur in REM sleep behavior disorder. Neurology, 72(6), 551-557.

Perlis, M. L. (1991). Sustained facial muscle activity during REM sleep.

Perlis, M. L., Giles, D. E., Fleming, G. M., Drummond, S. P., \& James, S. P. (1995). Sustained facial muscle activity during REM sleep and its correlation with depression. Journal of affective disorders, 35(4), 163-171.

Schmidt, K. L., \& Cohn, J. F. (2001). Human facial expressions as adaptations: Evolutionary questions in facial expression research. American Journal of Physical Anthropology: The Official Publication of the American Association of Physical Anthropologists, 116(S33), 3-24.

R Core Team. (2020). R: a language and environment for statistical computing [Internet]. $R$ Foundation for Statistical Computing.

Reissland, N., Francis, B., Mason, J., \& Lincoln, K. (2011). Do facial expressions develop before birth?. PLoS One, 6(8), e24081. 
Reissland, N., Francis, B., \& Mason, J. (2013). Can healthy fetuses show facial expressions of "pain" or "distress"? PLoS One, 8(6), e65530.

Rivera-Garcia, A., Ramirez-Salado, I., Corsi-Cabrera, M., \& Calvo, J. (2011). Facial muscle activation during sleep and its relation to the rapid eye movements of REM sleep. Journal of Sleep Research, 20,82-91. 
Table 1. Clinical characteristics of the groups

\begin{tabular}{|l|c|c|c|c|c|}
\hline & $\begin{array}{c}\text { Healthy } \\
\text { subjects }\end{array}$ & $\begin{array}{c}\text { Patients } \\
\text { without } \\
\text { parasomnia }\end{array}$ & $\begin{array}{c}\text { Patients with } \\
\text { DOA }\end{array}$ & $\begin{array}{c}\text { Patients } \\
\text { with RBD }\end{array}$ & $\mathrm{P}^{1}$ \\
\hline Subjects, N & 29 & 29 & 15 & 18 & - \\
\hline $\begin{array}{l}\text { Recorded } \\
\text { nights, N }\end{array}$ & 31 & 37 & 22 & 24 & - \\
\hline $\begin{array}{l}\text { Sex ratio, } \\
\text { male (\%) }\end{array}$ & $\begin{array}{l}15 / 29 \\
(51.7)\end{array}$ & $12 / 29(41.4)$ & $8 / 15(53.3)$ & $11 / 18(61.1)$ & 0.6 \\
\hline Age, years & $26.9 \pm$ & $50.5 \pm 15.2$ & $\begin{array}{c}32.2 \pm 14.5 \\
\mathrm{~d}, \mathrm{e}\end{array}$ & $61.6 \pm 13.6$ & $<0.0001$ \\
\hline $\begin{array}{l}\text { Epworth } \\
\text { sleepiness } \\
\text { score }\end{array}$ & $6.1 \pm 3.9^{\mathrm{a}, \mathrm{c}}$ & $12.1 \pm 6.1$ & $10.2 \pm 3.9$ & $10.6 \pm 5.9$ & 0.0002 \\
\hline
\end{tabular}

${ }^{1}$ Kruskal-Wallis rank test or Fisher's exact test. Post hoc Bonferroni correction $(\mathrm{p}<$ 0.008 ) for comparisons of healthy subjects vs. non-parasomniac patients ${ }^{\mathrm{a}}$, vs. patients with $D A^{b}$ and vs. patients with $\mathrm{RBD}^{\mathrm{c}}$; patients with $\mathrm{DOA}$ vs. nonparasomniac patients ${ }^{d}$ and vs. patients with $\mathrm{RBD}^{\mathrm{e}}$. DOA: disorders of arousal; RBD: REM sleep behaviour disorder. 
Table 2. Percentage of nights containing at least one brief or prolonged frowning or raised eyebrows, according to the sleep stage and participant groups.

\begin{tabular}{|c|c|c|c|c|c|}
\hline Group & $\begin{array}{l}\text { Healthy } \\
\text { subjects }\end{array}$ & $\begin{array}{c}\text { Patients } \\
\text { without } \\
\text { parasomnia }\end{array}$ & $\begin{array}{c}\text { Patients } \\
\text { With DOA }\end{array}$ & $\begin{array}{c}\text { Patients } \\
\text { With RBD }\end{array}$ & $\begin{array}{l}\text { Fisher } \\
\text { test, } P\end{array}$ \\
\hline $\begin{array}{l}\text { No of } \\
\text { participants }\end{array}$ & 29 & 29 & 15 & 18 & NA \\
\hline Nights, No & 31 & 37 & 22 & 24 & NA \\
\hline \multicolumn{6}{|c|}{ Frowns (E1), $N(\%)$ of nights with } \\
\hline TST & $31(100)$ & $35(95)$ & $22(100)$ & $24(100)$ & 0.34 \\
\hline N1 & $1(3)$ & $1(3)$ & $1(5)$ & $4(17)$ & 0.15 \\
\hline N2 & $27(87)$ & $27(74)$ & $21(95)$ & $22(92)$ & 0.1 \\
\hline N3 & $24(77)$ & $17(46)^{d}$ & $22(100)^{f}$ & $16(67)$ & $<0.0001$ \\
\hline REM sleep & $25(81)$ & $24(65)$ & $17(77)$ & $22(92)$ & 0.1 \\
\hline \multicolumn{6}{|c|}{ Brief (<1sec) frowns (E1a), N (\%) of nights with } \\
\hline TST & $31(100)$ & $35(95)$ & $21(95)$ & $24(100)$ & 0.41 \\
\hline $\mathrm{N} 1$ & 1 (3) & $1(3)$ & $1(5)$ & $4(17)$ & 0.15 \\
\hline N2 & $27(87)$ & $27(73)$ & $21(95)$ & $22(92)$ & 0.1 \\
\hline N3 & $24(77)^{a}$ & $16(43)^{d}$ & $21(95)$ & $16(67)$ & 0.0002 \\
\hline REM sleep & $25(81)$ & $24(65)$ & $16(73)$ & $22(92)$ & 0.09 \\
\hline \multicolumn{6}{|c|}{ Prolonged (> 1sec) frowns (E1b), N (\%) of nights with } \\
\hline TST & $19(61)$ & $15(39)^{\mathrm{d}, \mathrm{e}}$ & $18(86)$ & $19(79)$ & 0.0005 \\
\hline N1 & $0(0)$ & $0(0)$ & $0(0)$ & $0(0)$ & NA \\
\hline $\mathrm{N} 2$ & $12(39)$ & $8(22)$ & $12(55)$ & $11(46)$ & 0.06 \\
\hline N3 & $2(6)$ & $3(8)$ & $5(23)$ & $2(8)$ & 0.29 \\
\hline REM sleep & $13(42)$ & $6(16)^{d, e}$ & $12(55)$ & $17(71)$ & 0.0001 \\
\hline \multicolumn{6}{|c|}{ Eyebrows raising (E2), $\mathrm{N}(\%)$ of nights with } \\
\hline TST & $14(45)^{c}$ & $14(39)^{\mathrm{e}}$ & $13(57)$ & $21(88)$ & 0.0007 \\
\hline N1 & $2(6)$ & $0(0)$ & $0(0)$ & $1(4)$ & 0.35 \\
\hline $\mathrm{N} 2$ & $8(26)$ & $10(27)$ & $8(36)$ & $13(54)$ & 0.12 \\
\hline N3 & $7(23)$ & $5(14)$ & $5(23)$ & $4(17)$ & 0.73 \\
\hline REM sleep & $9(29)^{c}$ & $6(16)^{e}$ & $10(45)$ & $18(75)$ & $<0.0001$ \\
\hline
\end{tabular}


Post hoc tests with Bonferroni corrections $(p<0.008)$ for comparisons of healthy subjects vs. patients without parasomnia ${ }^{a}$, vs. patients with $D O A^{b}$, and vs. patients with $\mathrm{RBD}^{\mathrm{c}}$; patients without parasomnia vs. patients with $\mathrm{DOA}^{\mathrm{d}}$ and vs. patients with $\mathrm{RBD}^{\mathrm{e}}$; patients with DOA vs. patients with RBD'. DOA: disorders of arousal; RBD: REM sleep behaviour disorder; TST: total sleep time. 
Table 3. Frequency of total EMG activations of the corrugator, activations without observable movements, and activations with brief or prolonged frowning and raised eyebrows depending on the stage of sleep and the subject group.

\begin{tabular}{|c|c|c|c|c|c|}
\hline & $\begin{array}{l}\text { Healthy } \\
\text { subjects }\end{array}$ & $\begin{array}{l}\text { Non } \\
\text { parasomniac } \\
\text { patients }\end{array}$ & $\begin{array}{l}\text { DOA } \\
\text { patients }\end{array}$ & $\begin{array}{l}\text { RBD } \\
\text { patients }\end{array}$ & $\begin{array}{l}\text { Kruskal- } \\
\text { Wallis rank } \\
\text { test, } p\end{array}$ \\
\hline \multicolumn{6}{|c|}{ All EMG activation $(E 0+E 1+E 2): n / h r$ of sleep } \\
\hline TST & $\begin{array}{c}8.14 \pm \\
5.47^{\mathrm{a}}\end{array}$ & $\begin{array}{l}4.15 \pm \\
3.71^{\mathrm{d}, \mathrm{e}}\end{array}$ & $\begin{array}{c}10.02 \pm \\
7.47\end{array}$ & $\begin{array}{c}13.08 \pm \\
7.12\end{array}$ & $<0.0001$ \\
\hline N1 & $1.32 \pm 2.28$ & $0.73 \pm 2.78$ & $\begin{array}{l}3.86 \pm \\
11.25\end{array}$ & $2.31 \pm 4.84$ & 0.26 \\
\hline N2 & $4.85 \pm 3.89$ & $3.4 \pm 4.09$ & $7.13 \pm 5.17$ & $7.39 \pm 7.12$ & 0.0004 \\
\hline N3 & $6.36 \pm 6.4$ & $3.95 \pm 4.37^{d}$ & $8.85 \pm 7.33$ & $4.44 \pm 3.27$ & 0.008 \\
\hline REM sleep & $\begin{array}{r}20.27 \pm \\
13.6^{\mathrm{a}, \mathrm{c}}\end{array}$ & $7.83 \pm 8.65^{\mathrm{e}}$ & $\begin{array}{c}19.55 \pm \\
17.6\end{array}$ & $\begin{array}{c}44.81 \pm \\
34.2\end{array}$ & $<0.0001$ \\
\hline \multicolumn{6}{|c|}{ EMG activation without observable face movement $(E 0): n / h r$ of sleep } \\
\hline TST & $5.64 \pm 4.52$ & $\begin{array}{l}2.87 \pm \\
2.75^{\mathrm{d}, \mathrm{e}}\end{array}$ & $5.82 \pm 4.19$ & $7.74 \pm 6.11$ & $<0.0001$ \\
\hline N1 & $1.05 \pm 2.13$ & $0.64 \pm 2.67$ & $\begin{array}{l}3.76 \pm \\
11.24\end{array}$ & $0.9 \pm 2.75$ & 0.22 \\
\hline N2 & $3.32 \pm 3.3$ & $2.35 \pm 2.95$ & $4.29 \pm 3.42$ & $4.8 \pm 5.5$ & 0.01 \\
\hline N3 & $4.24 \pm 4.81$ & $2.73 \pm 2.96$ & $5.91 \pm 5.04$ & $2.89 \pm 2.76$ & 0.02 \\
\hline REM sleep & $\begin{array}{c}14.21 \pm \\
10.5^{\mathrm{a}}\end{array}$ & $5.23 \pm 6.4^{\mathrm{e}}$ & $\begin{array}{l}10.8 \pm \\
10.16\end{array}$ & $\begin{array}{c}27.17 \pm \\
27.93\end{array}$ & $<0.0001$ \\
\hline \multicolumn{6}{|c|}{ Frowns $(E 1): n / h r$ of sleep } \\
\hline TST & $\begin{array}{c}2.33 \pm \\
1.97^{\mathrm{a}}\end{array}$ & $\begin{array}{l}0.98 \pm \\
0.87^{\mathrm{d}, \mathrm{e}}\end{array}$ & $3.75 \pm 3.44$ & $3.92 \pm 2.37$ & $<0.0001$ \\
\hline N1 & $0.06 \pm 0.33$ & $0.1 \pm 0.58$ & $0.1 \pm 0.45$ & $1 \pm 2.65$ & 0.22 \\
\hline N2 & $1.44 \pm 1.09$ & $0.7 \pm 0.89^{d}$ & $2.42 \pm 1.82$ & $1.98 \pm 2.14$ & $<0.0001$ \\
\hline N3 & $1.83 \pm 2.07$ & $1.06 \pm 2^{d}$ & $2.77 \pm 2.49$ & $1.33 \pm 1.46$ & 0.0006 \\
\hline REM sleep & $\begin{array}{c}5.76 \pm \\
6.85^{c}\end{array}$ & $1.94 \pm 2.16^{\mathrm{e}}$ & $8.2 \pm 9.03$ & $\begin{array}{c}13.08 \pm \\
9.22\end{array}$ & $<0.0001$ \\
\hline
\end{tabular}




\begin{tabular}{|c|c|c|c|c|c|}
\hline \multicolumn{6}{|c|}{ Brief $(<1 \mathrm{sec})$ frowning $(\mathrm{E} 1 \mathrm{a}): \mathrm{n} / \mathrm{hr}$ of sleep } \\
\hline TST & $\begin{array}{c}2.07 \pm \\
1.72^{\mathrm{a}}\end{array}$ & $\begin{array}{l}0.86 \pm \\
0.72^{\mathrm{d}, \mathrm{e}}\end{array}$ & $3.27 \pm 3.08$ & $2.79 \pm 1.56$ & $<0.0001$ \\
\hline N1 & $0.06 \pm 0.33$ & $0.1 \pm 0.58$ & $0.1 \pm 0.45$ & $1 \pm 2.65$ & 0.11 \\
\hline N2 & $1.28 \pm 0.97$ & $0.61 \pm 0.71^{d}$ & $2.12 \pm 1.55$ & $1.71 \pm 1.8$ & $<0.0001$ \\
\hline N3 & $1.75 \pm 1.95$ & $1 \pm 1.93^{d}$ & $2.55 \pm 2.24$ & $1.25 \pm 1.44$ & 0.0008 \\
\hline $\begin{array}{l}\text { REM } \\
\text { Sleep }\end{array}$ & $4.99 \pm 5.7$ & $1.7 \pm 1.77^{\mathrm{e}}$ & $6.88 \pm 7.98$ & $8.53 \pm 5.95$ & $<0.0001$ \\
\hline \multicolumn{6}{|c|}{ Prolonged (>1sec) frowning (E1b) : n/hr of sleep } \\
\hline TST & $\begin{array}{c}0.26 \pm \\
0.34^{\mathrm{a}}\end{array}$ & $\begin{array}{l}0.12 \pm \\
0.23^{\mathrm{d}, \mathrm{e}}\end{array}$ & $0.49 \pm 0.52$ & $1.12 \pm 1.43$ & $<0.0001$ \\
\hline N1 & $0 \pm 0$ & $0 \pm 0$ & $0 \pm 0$ & $0 \pm 0$ & NA \\
\hline N2 & $0.17 \pm 0.26$ & $0.11 \pm 0.26$ & $0.3 \pm 0.4$ & $0.27 \pm 0.49$ & 0.06 \\
\hline N3 & $0.07 \pm 0.29$ & $0.06 \pm 0.24$ & $0.22 \pm 0.48$ & $0.07 \pm 0.26$ & 0.23 \\
\hline REM sleep & $\begin{array}{c}0.78 \pm \\
1.56^{\mathrm{c}}\end{array}$ & $\begin{array}{l}0.24 \pm \\
0.73^{\mathrm{d}, \mathrm{e}}\end{array}$ & $1.32 \pm 1.82$ & $4.55 \pm 5.57$ & $<0.0001$ \\
\hline \multicolumn{6}{|c|}{ Raised eyebrows (E2) $: \mathrm{n} / \mathrm{hr}$ of sleep } \\
\hline TST & $\begin{array}{c}0.17 \pm \\
0.23^{c}\end{array}$ & $0.31 \pm 0.75^{e}$ & $0.44 \pm 1.02^{f}$ & $1.42 \pm 1.33$ & $<0.0001$ \\
\hline N1 & $0.21 \pm 0.86$ & $0 \pm 0$ & $0 \pm 0$ & $0.38 \pm 1.88$ & NA \\
\hline N2 & $0.1 \pm 0.18$ & $0.33 \pm 1.1$ & $0.41 \pm 1.37$ & $0.65 \pm 0.84$ & 0.03 \\
\hline N3 & $0.29 \pm 0.81$ & $0.15 \pm 0.47$ & $0.18 \pm 0.4$ & $0.23 \pm 0.61$ & 0.79 \\
\hline REM sleep & $0.3 \pm 0.52^{c}$ & $0.65 \pm 2.82^{\mathrm{e}}$ & $0.53 \pm 0.72^{\dagger}$ & $4.55 \pm 4.74$ & $<0.0001$ \\
\hline
\end{tabular}

Post hoc tests with Bonferroni corrections $(p<0.008)$ for comparisons of healthy subjects vs. non-parasomniac patients ${ }^{\mathrm{a}}$, vs. DOA patients ${ }^{\mathrm{b}}$, and vs. RBD patients $\mathrm{s}^{\mathrm{c}}$; non-parasomniac patients vs. DOA patients ${ }^{d}$, vs. RBD patients ${ }^{\mathrm{e}}$; and DOA patients vs. RBD patients ${ }^{\dagger}$ 
Figure legends

Figure 1 - Illustrations of the facial expressions. E0: EMG activation without observable face movement; $E 1$ : frowns (E1a + E1b); E1a: brief $(<1 \mathrm{sec}$.) frowns; E1b: prolonged (>1 sec.) frowns; E2: raised eyebrows.

Figure 2A - Number of events (E0, E1a, E1b and E2) per hour of sleep (total sleep time). E0: EMG activation without observable face movement; E1a: brief ( $<1 \mathrm{sec})$ frowns; E1b: prolonged (>1 sec) frowns; E2: raised eyebrows. Figure 2B - Number of total EMG activations (E0 + E1 + E2) per hour in the different sleep stages (N1, N2, N3 and REM sleep). E1: frowns. Figure $2 \mathrm{C}-$ Number of frowns (E1) per hour in the different sleep stages (N1, N2, N3 and REM sleep). For Figures 2A, 2B and 2C: measures are expressed as the mean \pm SEM; asterisks indicate the levels of statistical significance: ${ }^{*} P<0.01$ and ${ }^{* * *} \mathrm{P}<0.0001$ for the comparisons between event types or sleep stages; N.S.: non-significant $(P>0.05)$.

Figure 3 - Illustrations of negative expressions in patients with REM sleep behaviour disorder (the facial details but not the expression were changed to ensure anonymity). 


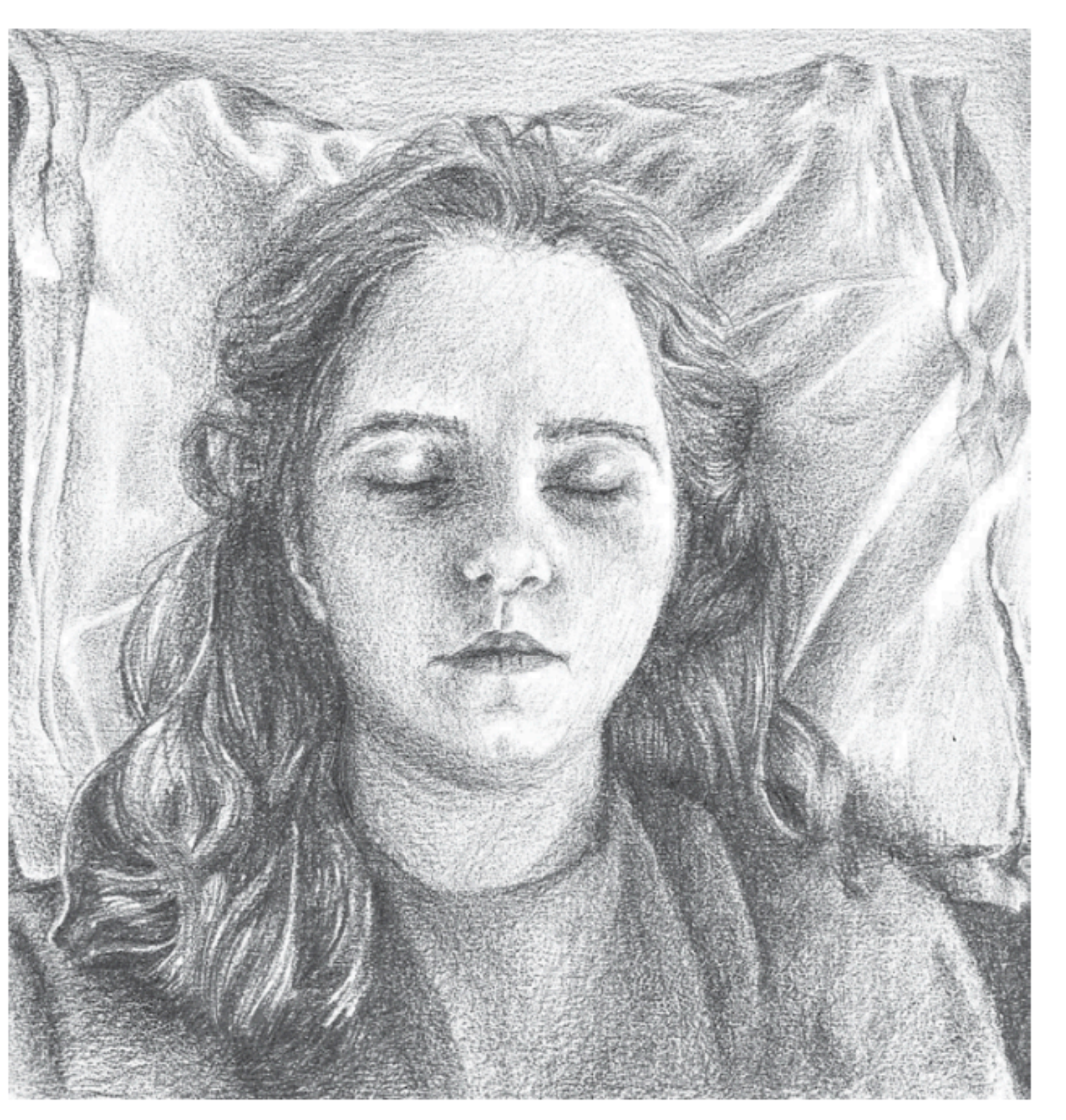

servable face

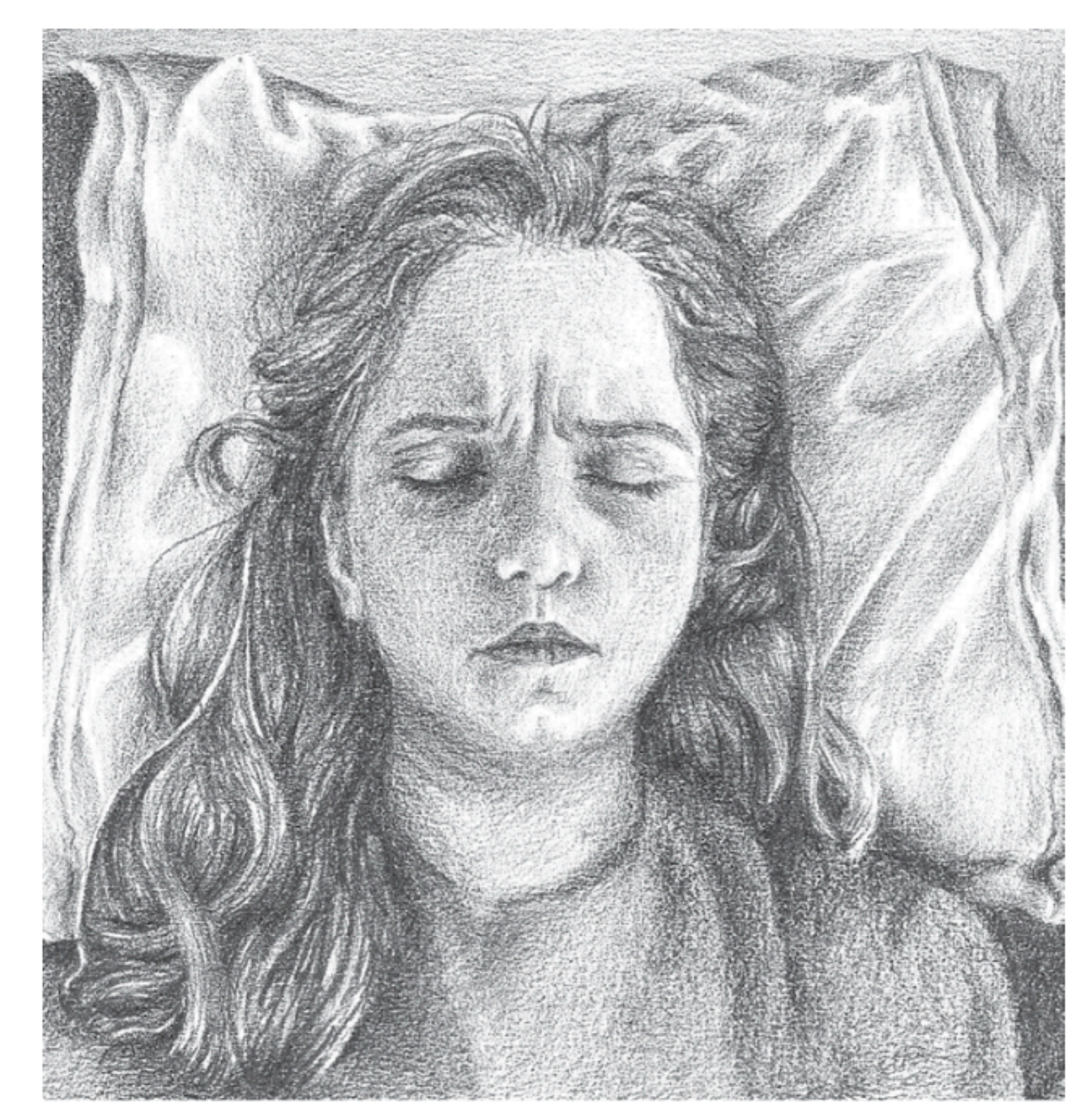

EMG

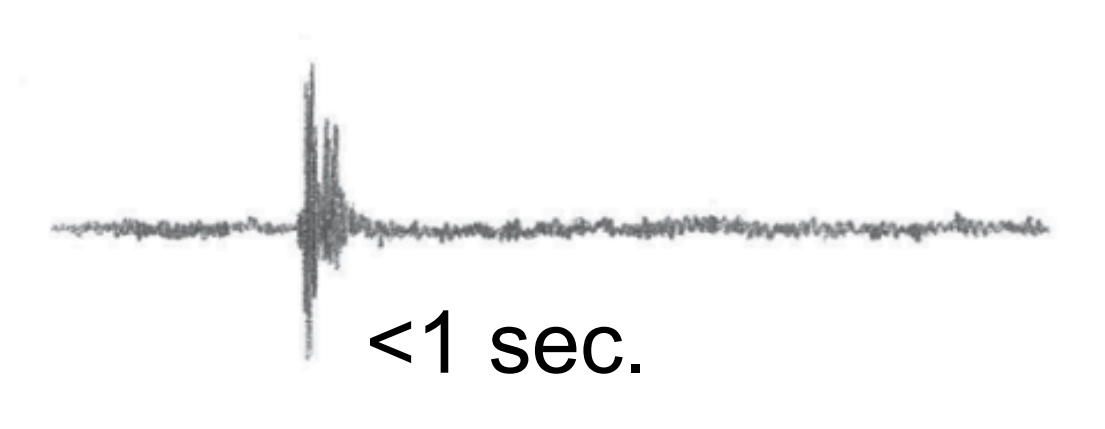

E1a: brief ( $<1 \mathrm{sec}$.) frowning

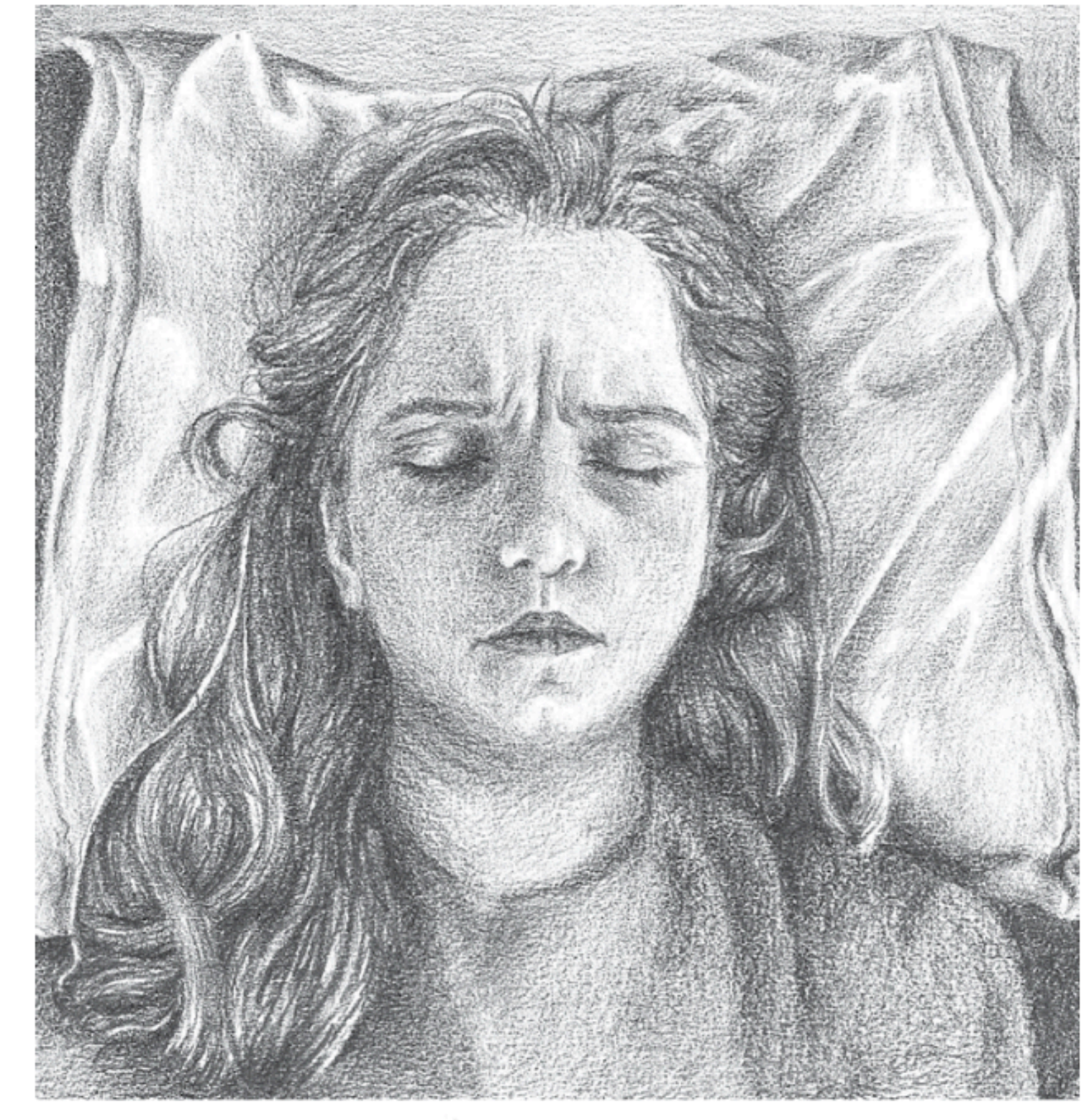

EMG

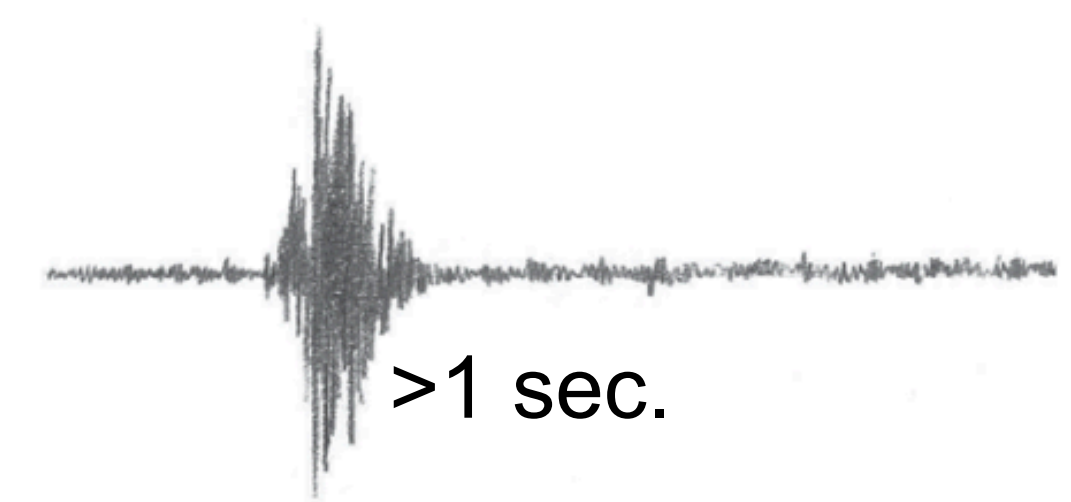

E1b: prolonged (>1 sec.) frowning

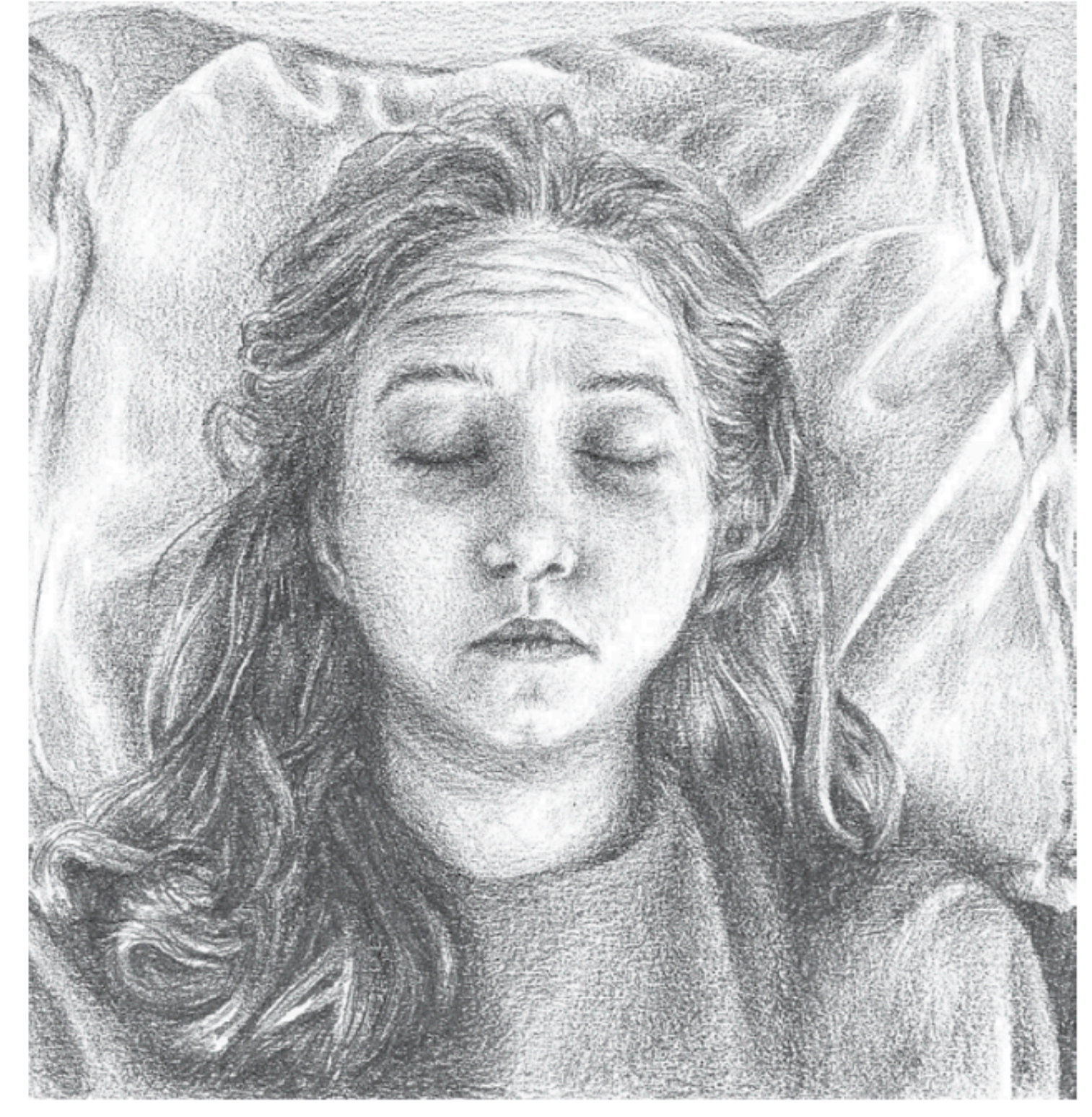

E2: raised eyebrows

E1: frowns 

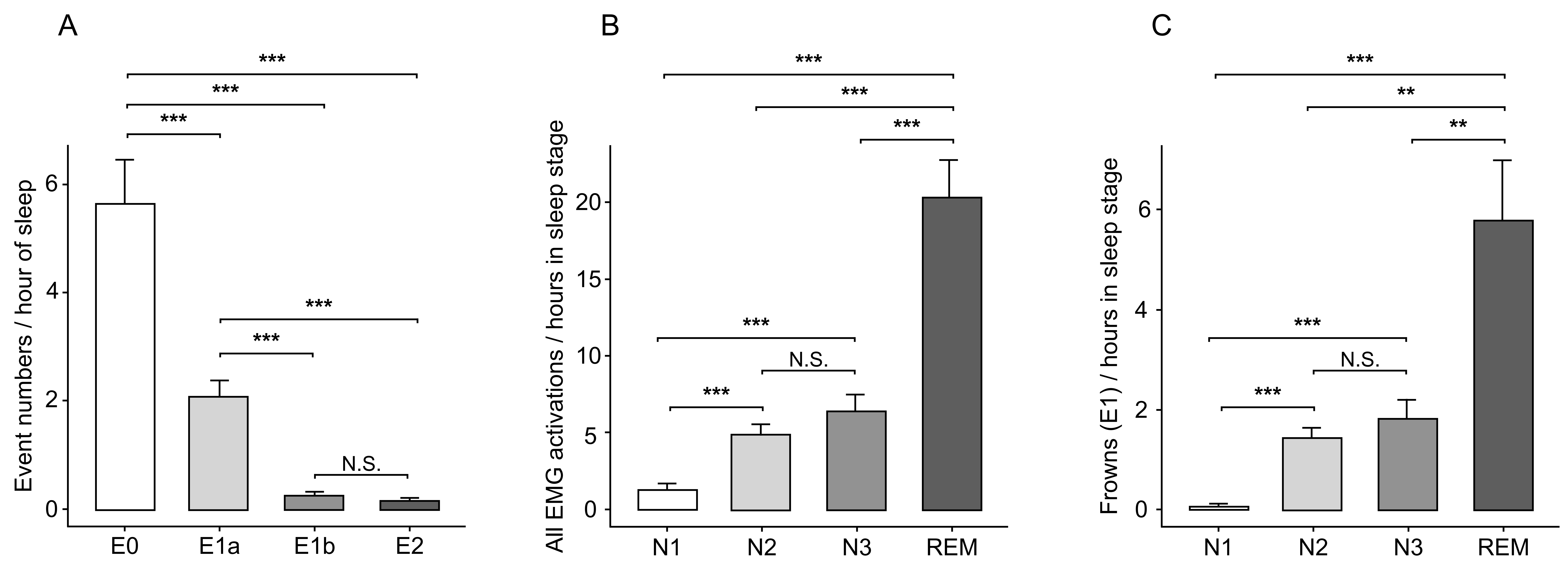


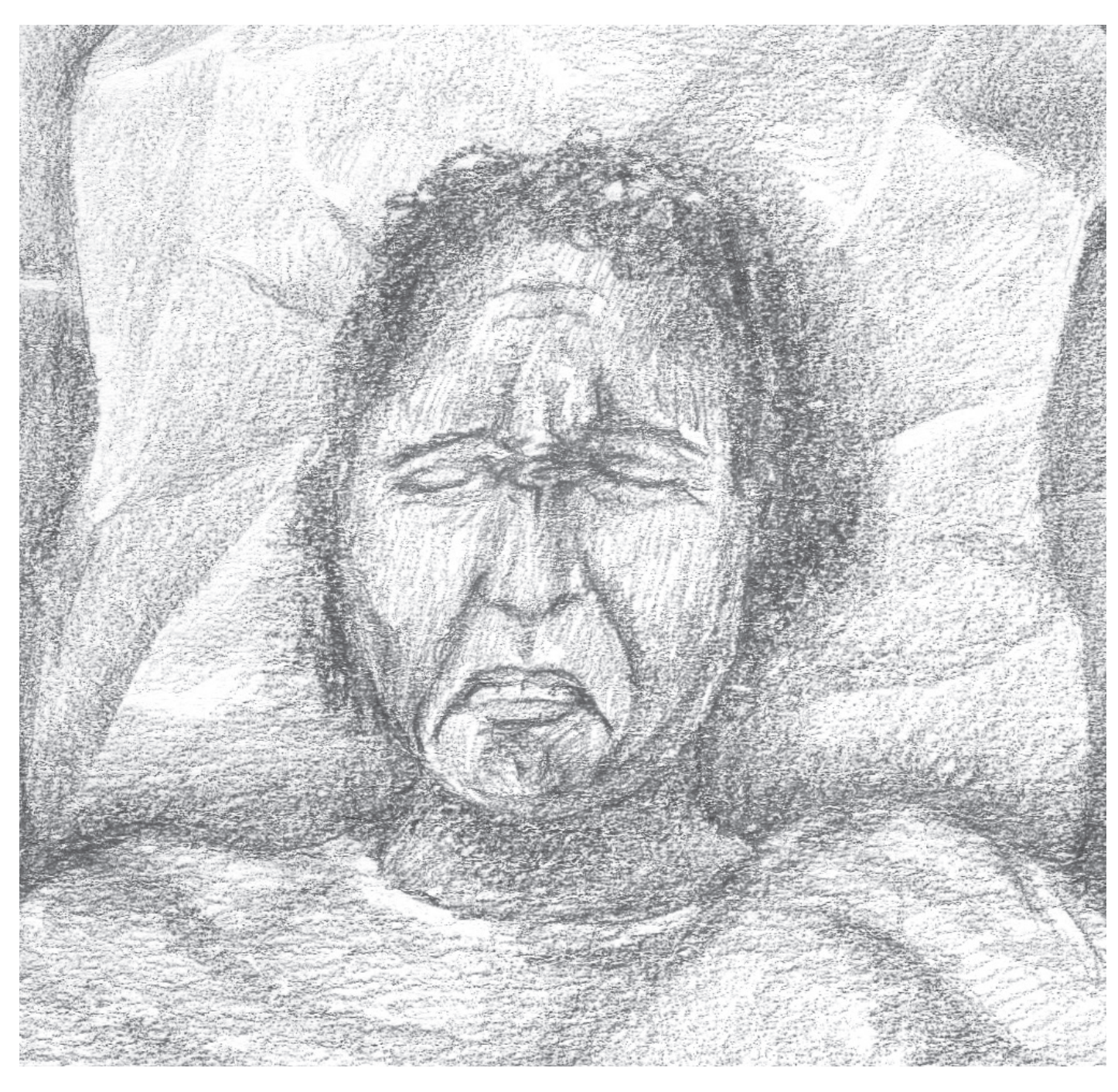

Pain

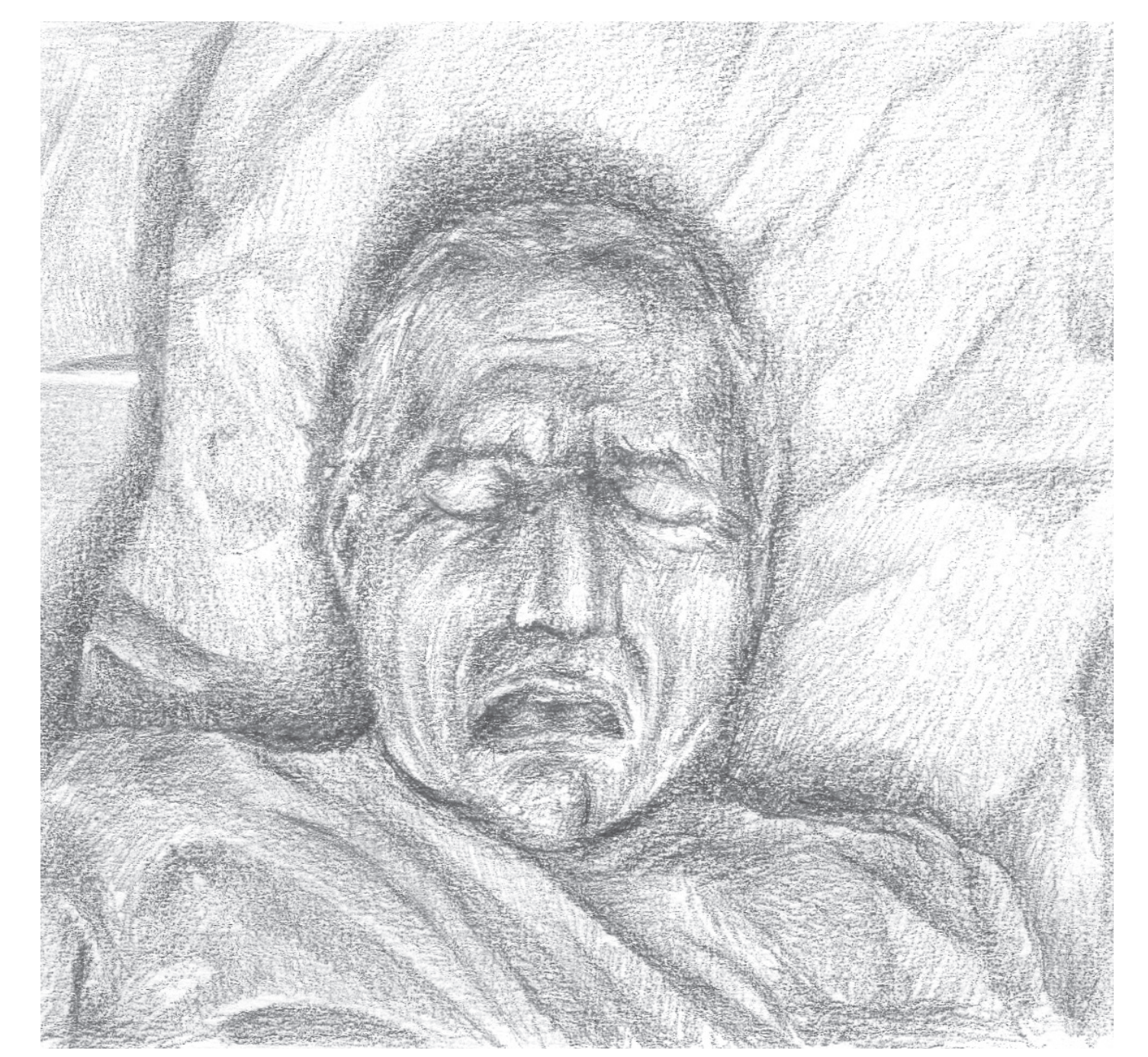

Pain with a cry

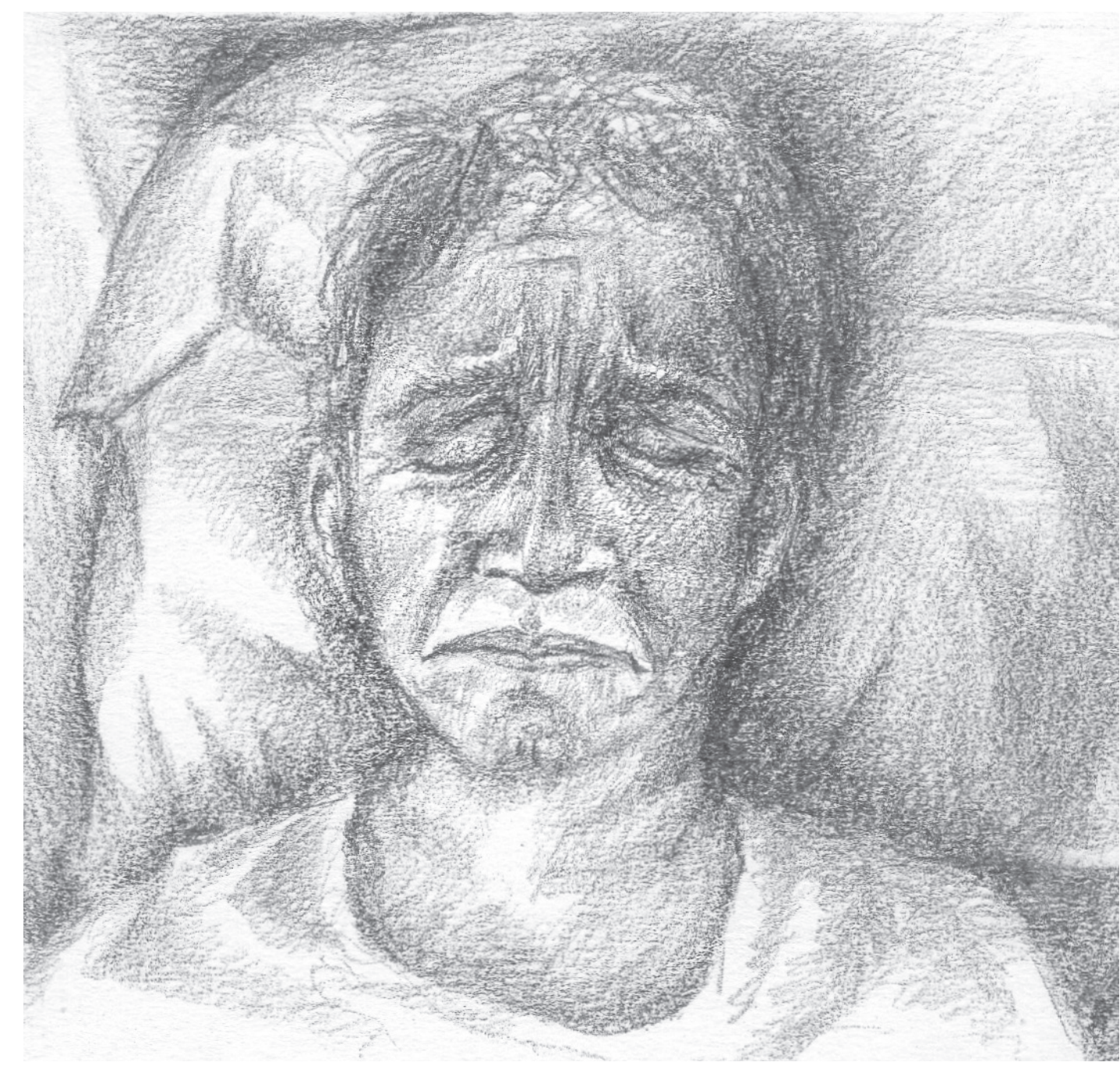

Sadness
Anger 